\title{
Biologic agents perception in patients attending for the first-time to psoriasis centers: a multicenter Italian survey
}

\author{
Maria LUCA 1, Maria L. MUSUMECI 1, Federico BARDAZZI 2, Concetta POTENZA 3, \\ Nicoletta BERNARDINI ${ }^{3}$, Francesca FERRARA 2, Alessandra PAVONE 1, Giuseppe MICALI 1 *
}

${ }^{1}$ Department of Dermatology, G. Rodolico Hospital, Policlinico-Vittorio Emanuele University Hospital, University of Catania, Catania, Italy; ${ }^{2}$ Division of Dermatology, Department of Specialized, Clinical and Experimental Medicine, University of Bologna, Bologna, Italy; ${ }^{3}$ Daniele Innocenzi Unit of Dermatology, Department of Medical and Surgical Sciences and Biotechnologies, Polo Pontino, A. Fiorini Hospital, Sapienza University, Rome, Italy

*Corresponding author: Giuseppe Micali, Department of Dermatology, G. Rodolico Hospital, Policlinico-Vittorio Emanuele University Hospital, University of Catania, Catania, Italy. E-mail: cldermct@gmail.com

\section{A B S T R A C T}

BACKGROUND: Inadequate treatment and delayed access to care represent critical issues regarding psoriasis. In Italy, patients treated with biologics are scanty and patients' misinformation could interfere with both biologics prescription and access to care. Literature provide data on disease awareness and perception about biologics in already-treated patients, but there is a lack of information concerning patients never treated with such drugs.

METHODS: We conducted a national survey including three academic-based psoriasis care centers at Bologna, Rome and Catania. A questionnaire named Psoriatic Patients's Awareness on Biologics (PPAB) was administered to patients naïve for biologics and accessing for the fist-time to a psoriasis care center.

RESULTS: Patients from Northern Italy referred to more reliable sources of information and awareness on biologics decreased from North to South. The increase of the Psoriasis Area Severity Index was associated to unawareness about biologics and impaired self-evaluation on the eligibility to treatment. Patients under systemic conventional /multiple therapy were more likely to be unaware about biologics.

CONCLUSIONS: Our survey demonstrates that psoriatic patients' awareness is still an unmet need. For more, patients potentially eligible for biologics (severe or treated with systemic conventional/multiple therapy) were less informed. We believe that patients' misinformation could have delayed the access to a psoriasis care center, so that when patients sought help their condition was more severe and required systemic conventional/multiple therapy. Our results reiterate the importance of physicians in the information process and urge the need of a common network among office dermatologists, general practitioners and psoriasis care centers.

(Cite this article as: Luca M, Musumeci ML, Bardazzi F, Potenza C, Bernardini N, Ferrara F, et al. Biologic agents perception in patients attending for the first-time to psoriasis centers: a multicenter Italian survey. G Ital Dermatol Venereol 2020;155:150-4. DOI: 10.23736/S0392-0488.17.05754-6) KeY words: Psoriasis; Communication; Awareness.

$\mathrm{P}$ soriasis is a chronic skin disease burdened by high social costs and serious consequences on the patients' psychophysical health.1,2 The introduction of biologics represents a new era for the treatment of psoriasis, however international studies highlight their underprescription. The main barrier to the prescription of biologics had been since here reconducted to the physicians' concerns about safety and costs. ${ }^{3,} 4$ In Italy, about 1.8 million people suffer from psoriasis, more than 500,000 being moderate-severe. ${ }^{5}$ Assuming a huge proportion of not-eligible patients, the prescription of less than 20,000 biologics/year is still amazingly low. ${ }^{6}$ It is worth wondering whether patientsrelated factors, too, could contribute to biologics underprescription. Literature data generally provide a picture of an unsatisfying management of psoriasis, as well as a general disease unawareness among patients. A multicenter Italian survey reported that patients were not fully aware of their own disease and the strategies to cope with it, for instance adjusting their lifestyle. ${ }^{7}$ In a US study conducted on 1005 psoriatic patients, $42.6 \%$ of patients had never been visited 


\section{COPYRIGHT $^{\circledR} 2020$ EDIZIONI MINERVA MEDICA}

by an health care provider in the last year. ${ }^{8}$ These alarming data have been recognized as a global concern and the World Health Organization claimed incorrect or delayed diagnosis, inadequate treatment options and delayed access to care as critical issues regarding psoriasis. ${ }^{9}$ Physicians' efforts should then focus on identifying the flaws that could lead to an unsatisfying management of psoriasis. Identifying patients' awareness could represent one of the strategies needed to face these critical issues as patients' misinformation could interfere with both biologics prescription and access to care, favoring the diffusion of prejudices and false beliefs. Literature provides data on the awareness and perception of biologics in patients already treated with such drugs, who usually express satisfaction towards them, despite their anxiety for injections and concerns about side-effects. ${ }^{8}, 10$ As a result, patients under biologic therapy usually show a good adherence to treatment. ${ }^{11}$ On the contrary, there is a lack of data regarding the awareness on biologics in psoriatic patients never treated with such drugs. In order to address this issue, we conducted a multicenter national survey administering to the patients a questionnaire designed ad hoc by the investigators.

\section{Materials and methods}

\section{Study design}

This was a multicenter survey including three academicbased psoriasis care centers at Bologna (BO), Rome (RM) and Catania (CT), located respectively in Northern, Central and Southern Italy, conducted during a three-month period (January 2017-March 2017). The study was conducted in accordance to the principles of the Helsinki Declaration and Good Clinical Practices. Each patient signed an informed consent.

\section{Study population}

Consecutive outpatients were enrolled if they met the following eligibility criteria: were aged $>18$ years, had a confirmed diagnosis of psoriasis (regardless disease severity), had never been treated with biologics, were accessing for the first-time to a psoriasis care center.

\section{Questionnaire}

The investigators designed a questionnaire, named Psoriatic Patients's Awareness on Biologics (PPAB) (Table I). This was a self-administered "true/false" questionnaire intended for psoriatic patients consisting of 14 items (in Italian) addressing the following topics: awareness on pso- riasis and its treatments in general (items 1-4); patients' knowledge about biologics (item 5: "I have heard about biologic drugs"); perception and awareness about biologics (items 6-14, reserved to those patients who answered "true" to item 5). In addition, the questionnaire had a section where the patients were asked to acknowledge their source of information on biologics, both selecting from examples (e.g. acquaintances, other psoriatic patients) and freely writing other, not-enlisted, sources. Newspapers, TV, internet, etc. were classified under the term "media," while both primary and specialty doctors were classified under the term "physicians" (Table I).

\section{Data collection}

After the verification of the eligibility criteria, the patients were informed about the study and asked if they were willing to participate. Previous written informed consent, the patients were required to fill in the questionnaire before their scheduled outpatient visit. In addition, the following demographic and clinical data were recorded: age, sex, years of education, disease duration, Psoriasis Area Severity Index (PASI), ${ }^{12}$ presence of arthritis, current dermatological therapy (Table II).

\section{Statistical analysis}

The statistical analysis was performed using the Statistical Package for the Social Sciences (SPSS) 17.0 software. Qualitative variables were expressed as number and percentage and compared through the $\chi^{2}$ test. Quantitative variables were expressed as mean \pm standard deviation and compared through the ANOVA test. A multivariate analysis was performed in order to investigate on the strength of the associations. The level of significance was set at $\mathrm{P} \leq 0.05$. The analysis of the answers given at the PPAB pertained the whole sample from item 1 to 5 . The analysis from item 6 to 14 pertained only the patients who answered "true" to item 5 .

\section{Results}

\section{Study population}

One hundred and seventy-nine patients (60 from RM and $\mathrm{CT}, 59$ from $\mathrm{BO}$ ) were enrolled. The three groups (BO, RM, CT) did not differ in terms of age, sex and years of education. Disease duration and PASI score were significantly higher respectively in $\mathrm{BO}$ and $\mathrm{CT}$. A higher percentage of untreated patients was recorded among the patients from CT, as well as a higher number of patients under topical therapy only (Table II). 


\section{COPYRIGHT ${ }^{\circledR} 2020$ EDIZIONI MINERVA MEDICA}

TABLE I.—Psoriatic patients'awareness on biologics (PPAB questionnaire).

\begin{tabular}{|c|c|c|c|c|}
\hline Item & $\begin{array}{l}\text { Northern Italy } \\
\text { (BO, N. 59) }\end{array}$ & $\begin{array}{l}\text { Central Italy } \\
(\text { RM, N. 60) }\end{array}$ & $\begin{array}{l}\text { Southern Italy } \\
\text { (CT, N. 60) }\end{array}$ & $\begin{array}{c}\mathrm{P} \\
\text { value }\end{array}$ \\
\hline 1. Therapies are almost always useless $(\mathrm{T})$ & $13(22 \%)$ & $14(23.3 \%)$ & $17(28.3 \%)$ & 0.700 \\
\hline 2. It is possible to recover from psoriasis for good $(\mathrm{F})$ & $48(81.4 \%)$ & $47(78.3 \%)$ & $45(75 \%)$ & 0.703 \\
\hline 3. The type of therapy is the same and does not relate to severity (F) & $55(93.2 \%)$ & $49(81.7 \%)$ & $52(86.7 \%)$ & 0.168 \\
\hline 4. The type of therapy changes if I have other associated disorders $(\mathrm{T})$ & $50(84.7 \%)$ & $50(83.3 \%)$ & $37(61.7 \%)$ & 0.004 \\
\hline 5. I have heard about "biologic drugs" (injections done periodically) (T) & $45(76.3 \%)$ & $42(70 \%)$ & $33(55 \%)$ & 0.040 \\
\hline Only patients answering " $T$ " at the previous item completed the questionnaire Biologic Drugs & $\begin{array}{l}\text { Northern Italy } \\
(\mathrm{BO}, \mathrm{N} .45)\end{array}$ & $\begin{array}{l}\text { Central Italy } \\
(\text { RM, N. 42) }\end{array}$ & $\begin{array}{l}\text { Southern Italy } \\
\text { (CT, N. 33) }\end{array}$ & \\
\hline 6. Are natural substances without side effects $(\mathrm{F})$ & $26(57.8 \%)$ & $25(59.5 \%)$ & $19(57.6 \%)$ & 0.981 \\
\hline 7. Make you recover for good and need to be withdrawn after a couple of years (F) & $38(84.4 \%)$ & $33(78.6 \%)$ & $26(78.8 \%)$ & 0.738 \\
\hline 8. Are more powerful then oral drugs $(\mathrm{T})$ & $29(64.4 \%)$ & $23(54.8 \%)$ & $21(63.6 \%)$ & 0.605 \\
\hline $\begin{array}{l}\text { 9. Are more appealing, because the patient does the injection and doesn't need to think about } \\
\text { taking the pills }(\mathrm{T})\end{array}$ & $25(55.6 \%)$ & $36(85.7 \%)$ & $23(69.7 \%)$ & 0.009 \\
\hline $\begin{array}{l}\text { 10. Can be prescribed to all the patients, both to those with few psoriatic lesions and those covered } \\
\text { with many psoriatic lesions }(\mathrm{F})\end{array}$ & $38(84.4 \%)$ & $25(59.5 \%)$ & $18(54.5 \%)$ & 0.008 \\
\hline 11. According to my current condition, I should be treated with a biologic drug $(\mathrm{T})$ & $23(51.1 \%)$ & $23(54.7 \%)$ & $18(54.5 \%)$ & 0.931 \\
\hline 12. Women under treatment with a biologic drug should avoid pregnancy $(\mathrm{T})$ & $29(64.4 \%)$ & $21(50 \%)$ & $16(48.5 \%)$ & 0.271 \\
\hline 13. I would gladly accept a therapy with a biologic drug $(\mathrm{T})$ & $38(84.4 \%)$ & $36(85.7 \%)$ & $25(75.8 \%)$ & 0.483 \\
\hline 14. I would be afraid of starting a therapy with a biologic drug $(\mathrm{T})$ & $12(26.7 \%)$ & $11(26.2 \%)$ & $14(42.4 \%)$ & 0.238 \\
\hline Source of information & $\begin{array}{l}\text { Northern Italy } \\
(\mathrm{BO}, \text { N. 45) }\end{array}$ & $\begin{array}{l}\text { Central Italy } \\
(\text { RM, N. 42) }\end{array}$ & $\begin{array}{l}\text { Southern Italy } \\
\text { (CT, N. 33) }\end{array}$ & \\
\hline Media (TV, newspaper, internet, etc.) & $15(33.3 \%)$ & $9(21.4 \%)$ & $10(30.3 \%)$ & 0.449 \\
\hline Other psoriatic patients & $1(2.2 \%)$ & $9(21.4 \%)$ & $3(9.1 \%)$ & 0.015 \\
\hline Acquaintances/family & $1(2.2 \%)$ & $7(11.7 \%)$ & $10(30.3 \%)$ & 0.003 \\
\hline Physicians (primary or specilaty doctors) & $18(40 \%)$ & $9(21.4 \%)$ & $2(6.1 \%)$ & 0.002 \\
\hline Multiple sources (association of the above mentioned sources) & $10(22.2 \%)$ & $8(19.1 \%)$ & $8(24.2 \%)$ & 0.858 \\
\hline
\end{tabular}

The table shows the pattern of answers for each item of the PPAB questionnaire designed by the investigators using an elementary terminology. The patients were asked to think about psoriasis when answering the questions. According to the importance of a positive or negative answer in terms of interpretation of the results, certain numbers and percentages refer to the positive answers (true-T), while others refer to the negative ones (false-F). For example, a positive answer at the item 5 indicated mistrust towards therapies, while a negative answer at the item 6 indicated awareness about the pharmacological nature of biologics. The values are reported as number and percentage. The $\mathrm{P}$ value obtained from the comparison between groups is also reported.

BO: Bologna; RM: Rome; CT: Catania.

TABLE II.-General characteristics of the sample.

\begin{tabular}{|c|c|c|c|c|}
\hline Characteristics of the sample & $\begin{array}{l}\text { Northern Italy } \\
\text { (BO, N. 59) }\end{array}$ & $\begin{array}{l}\text { Central Italy } \\
\text { (RM, N. 60) }\end{array}$ & $\begin{array}{c}\text { Southern Italy } \\
\text { (CT, N. 60) }\end{array}$ & $\mathrm{P}$ value \\
\hline Age & $47.4 \pm 15$ & $47.3 \pm 16.6$ & $47.8 \pm 15.2$ & 0.981 \\
\hline Males & $34(57.6 \%)$ & $29(48.3 \%)$ & $23(38.3 \%)$ & 0.109 \\
\hline Education & $12.5 \pm 3.3$ & $11.5 \pm 4.6$ & $10.8 \pm 3.7$ & 0.056 \\
\hline Disease duration & $16.4 \pm 14.2$ & $7.9 \pm 9.7$ & $13.9 \pm 11.3$ & $<0.001$ \\
\hline Psoriasis Area Severity Index & $7.5 \pm 5.1$ & $5.5 \pm 3.8$ & $11.5 \pm 13$ & $<0.001$ \\
\hline Psoriatic arthritis & $12(20.3 \%)$ & $13(21.7 \%)$ & $23(38.3 \%)$ & 0.047 \\
\hline Therapy & $\begin{array}{c}\text { Northern Italy } \\
\text { (BO, N. 59) }\end{array}$ & $\begin{array}{l}\text { Central Italy } \\
(\mathrm{RM}, \mathrm{N} .60)\end{array}$ & $\begin{array}{c}\text { Southern Italy } \\
\text { (CT, N. 60) }\end{array}$ & \\
\hline None & $2(3.4 \%)$ & $10(16.7 \%)$ & $17(28.3 \%)$ & 0.001 \\
\hline Topical therapy & $20(33.9 \%)$ & $23(38.3 \%)$ & $35(58.3 \%)$ & 0.022 \\
\hline Systemic conventional therapy & $13(22 \%)$ & $9(15 \%)$ & $7(11.7 \%)$ & 0.294 \\
\hline Phototherapy & $4(6.8 \%)$ & $6(10 \%)$ & 0 & 0.052 \\
\hline Multiple therapy (association between the above mentioned therapies) & $20(33.9 \%)$ & $12(20 \%)$ & $1(1.7 \%)$ & $<0.001$ \\
\hline
\end{tabular}

The table shows the general data recorded for each group. The values are reported as number and percentage or as mean \pm standard deviation. The $\mathrm{P}$ value obtained from the comparisons between groups is also reported. BO: Bologna; RM: Rome; CT: Catania. 


\title{
COPYRIGHT $^{(\odot)} 2020$ EDIZIONI MINERVA MEDICA
}

\author{
BIOLOGIC AGENTS PERCEPTION IN PATIENTS ATTENDING TO PSORIASIS CENTERS
}

\section{PPAB questionnaire}

All patients presented similar patterns of answer at the items pertaining awareness on psoriasis and its treatments in general (items 1-3), except for item 4: "The type of therapy changes if I have other associated disorders," where the percentage of correct answers (true) significantly decreased from North to South. The percentage of patients having heard about biologics (item 5), too, significantly declined from North to South (Table I). As previously mentioned, only those patients answering "true" to item 5 could access to the remaining items 6-14. Forty-five patients from BO, 42 from RM and 33 from CT were able to complete the questionnaire. The pattern of answers was similar for all the items, except for a significant difference about items 9 ("Biologics are more appealing, because the patient does the injection and doesn't need to think about taking the pills") and 10 ("Biologics can be prescribed to all the patients, both those with few psoriatic lesions and those covered with many psoriatic lesions"). In particular, the answer "true" to item 9 was more frequent among patients from RM, while the answer "false" to item 10 was more frequent among patients from BO (Table I). As regards the source of information, "Other psoriatic patients," "Acquaintances/family" and "Physicians" represented a significant source of information respectively for patients from RM, CT and BO (Table I). The multivariate analysis of the entire sample showed that the answer "false" to items 11 (pertaining the awareness on the eligibility criteria: "According to my current condition, I should be treated with a biologic drug") and 5 ("I have heard about biologics") was associated to PASI increase (OR 63, 95\%CI 8.7-454.2, $\mathrm{P}<0.001$; OR 0.92, 95\%CI 0.86-0.98, $\mathrm{P}=0.012$ ). Moreover, the answer "false" to item 5 was also associated to systemic conventional (OR $0.17,95 \% \mathrm{CI} 0.47-0.61$, $\mathrm{P}=0.007)$ and multiple therapy (OR $0.28,95 \% \mathrm{CI} 0.95$ $0.87, \mathrm{P}=0.028$ ).

Finally, the multivariate analysis showed that awareness (PPAB items) was not associated to age, sex, years of education, disease duration and psoriatic arthritis.

\section{Discussion}

Modern treatment of psoriasis is focused on a patient-centered approach that implies a more active role of patients in the decision-making phases..$^{13}$ To ensure a satisfying management, also in terms of adherence to treatment, patients should be fully aware of the disease and its therapy. However, literature data indicate that psoriatic patients' aware- ness is still an unmet need, ${ }^{7}$ as also confirmed by our study. The results from our survey showed that all the enrolled patients shared the same level of knowledge regardingpsoriasis and its treatment in general (items 1-3). However, awareness on the need of a personalized therapy according to the presence of other disorders (item 4) as well as if they had heard about biologics (item 5) significantly decreased from Northern to Southern Italy. The analysis of the remaining items $(6-8,11-14)$ showed a similar pattern of answers, while statistically significant differences were found for items 9 and 10. In particular, patients from RM showed to be more keen towards biologics, considering them more appealing compared to other systemic treatments (item 9). An explanation for this is that as they refer to other psoriatic patients as a source of information, they likely recorded statements of satisfaction by already-treated individuals. As regards item 10, patients from $\mathrm{BO}$ were more aware that the prescription of biologics is reserved to moderate-severe psoriasis and the reported source of information in this group, namely physicians, could explain their higher level of knowledge (items 4-5, 10). The importance of physicians has been highlighted in previous studies, suggesting that patients' awareness on psoriasis pathogenesis mostly rely on their general practitioners' advice.7 Unfortunately, the percentage of unreliable sources of information in our sample was quite high, with 34 out of 120 patients referring to media as a source of information.

Considering the whole sample the multivariate analysis showed that unawareness on biologics (item 5) and selfevaluation on the eligibility to treatment (item 11) were associated to PASI increase. Also, patients under systemic conventional/multiple therapy or potentially eligible for biologics (being affected by moderate-severe psoriasis) were less informed. Misinformation, delaying the access to psoriasis care centers (all the enrolled patients were at their first-time access), was responsible for the progressive worsening of the disease; we believe that when patients finally consulted with a dedicated center, the condition was so severe to be managed only with systemic conventional/ multiple therapy. In addition to delaying a proper access to care, misinformation could also contribute to undertreatment, thus affecting clinical outcome, as observed in patients from Southern Italy. Undertreatment of psoriasis, however, is a recognized global concern. A multinational survey conducted on more than 3000 psoriatic patients showed that " $45 \%$ of them had not seen a physician in a year, $>80 \%$ with $\geq 4$ palms body surface area and $59 \%$ affected from psoriatic arthritis were receiving no treatment or topical treatment only". Many patients did not refer to 


\section{COPYRIGHT $^{\circledR} 2020$ EDIZIONI MINERVA MEDICA}

an health care provider because they "did not believe an health care provider could help or their symptoms were not severe enough". Patients' unawareness was claimed as a possible reason of such a discrepancy between patients' perspective and treatment goals. ${ }^{14}$

Finally, our results demonstrated that awareness was not influenced by age, psoriatic arthritis, disease duration and years of education. These data differ from another study in which psoriatic arthritis and years of education were associated with significantly higher awareness/knowledge, while older age was inversely associated. ${ }^{7}$

\section{Conclusions}

Enhancing patients' awareness on biological treatment would result in a better disease management, improving patients' ability to cope with psoriasis and adherence to treatment, thus positively affecting the patients' quality of life. Based on our results, there is a need for a common network among office dermatologists, general practitioners and reference care centers for psoriasis. Similar studies with a larger sample size as well as data from other countries are desirable.

\section{References}

1. Feldman SR, Burudpakdee C, Gala S, Nanavaty M, Mallya UG. The economic burden of psoriasis: a systematic literature review. Expert Rev Pharmacoecon Outcomes Res 2014;14:685-705.

2. Luca M, Luca A, Musumeci ML, Fiorentini F, Micali G, Calandra C, Psychopathological variables and sleep quality in psoriatic patients. Int $\mathrm{J}$ Mol Sci 2016;17:E1184.
3. Nast A, Mrowietz U, Kragballe K, de Jong EM, Puig L, Reich K, et al. Barriers to the prescription of systemic therapies for moderate-to-severe psoriasis - a multinational cross-sectional study. Arch Dermatol Res 2013;305:899-907.

4. van de Kerkhof PC, Reich K, Kavanaugh A, Bachelez H, Barker J, Girolomoni $\mathrm{G}$, et al. Physician perspectives in the management of psoriasis and psoriatic arthritis: results from the population-based Multinational Assessment of Psoriasis and Psoriatic Arthritis survey. J Eur Acad Dermatol Venereol 2015;29:2002-10.

5. Colombo G, Altomare G, Peris K, Martini P, Quarta G, Congedo M, et al. Moderate and severe plaque psoriasis: cost-of-illness study in Italy. Ther Clin Risk Manag 2008;4:559-68.

6. The Italian Medicines Agency (AIFA). National report on medicines use in Italy. Year 2015 [Internet]. Available from: http://www.aifa.gov.it/ sites/default/files/OsMed_2015_Eng.pdf [cited 2017 May 30].

7. Bardazzi F, Amerio P, Amoruso G, Campanati A, Conti A, De Simone $\mathrm{C}$, et al.; Alphard study. Psoriasis awareness among Italian patients: results of a nationwide survey. G Ital Dermatol Venereol 2016;151:1-8.

8. Lebwohl MG, Kavanaugh A, Armstrong AW, Van Voorhees AS. US perspectives in the management of psoriasis and psoriatic arthritis: patient and physician results from the population-based multinational assessment of psoriasis and psoriatic arthritis (MAPP) survey. Am J Clin Dermatol 2016;17:87-97.

9. World Health Organization (WHO). Global report on psoriasis. Year 2016. [Internet]. Avaliable from: http://apps.who.int/iris/bitstre am/10665/204417/1/9789241565189_eng.pdf [cited 2017 June 5].

10. Kamangar F, Isip L, Bhutani T, Dennis M, Heller MM, Lee ES, et al. How psoriasis patients perceive, obtain, and use biologic agents: survey from an academic medical center. J Dermatolog Treat 2013;24:13-24.

11. Hsu DY, Gniadecki R. Patient adherence to biologic agents in psoriasis. Dermatology 2016;232:326-33.

12. Fredriksson T, Pettersson U. Severe psoriasis - oral therapy with a new retinoid. Dermatologica 1978;157:238-44.

13. Cordingley L, Nelson PA, Griffiths CE, Chew-Graham CA. Beyond skin: the need for a new approach to the management of psoriasis in primary care. Br J Gen Pract 2012;62:568-9.

14. Lebwohl MG, Bachelez H, Barker J, Girolomoni G, Kavanaugh A, Langley RG, et al. Patient perspectives in the management of psoriasis: results from the population-based Multinational Assessment of Psoriasis and Psoriatic Arthritis Survey. J Am Acad Dermatol 2014;70:871-81. e1, 30 .

Conflicts of interest.-The authors certify that there is no conflict of interest with any financial organization regarding the material discussed in the manuscript. Authors' contributions. - Maria Luca was a major contributor in writing the manuscript, contributed in designing the study and collecting the data; Maria L. Musumeci designed the study and contributed in writing the manuscript; Federico Bardazzi, Concetta Potenza, Nicoletta Bernardini and Francesca Ferrara contributed in collecting the data and interpreting the results; Alessandra Pavone contributed in collecting the data; Giuseppe Micali conceived the research and contributed in interpreting the results and writing the manuscript. All the authors read and approved the manuscript.

History. -Article first published online: November 30, 2017. - Manuscript accepted: October 5, 2017. - Manuscript received: August 5, 2017. 